06.3

\title{
Получение регулярных металлических и диэлектрических микроструктур на основе модифицированных при облучении полимерных пленок
}

\author{
(C) В.Е. Асадчиков ${ }^{1}$ С.А. Бедин ${ }^{1}$, В.В. Березкин ${ }^{1}$, А.Б. Васильев ${ }^{1}$, Ю.В. Григорьев ${ }^{1}$, И.Г. Дьячкова ${ }^{1}$, \\ А.А. Коновко ${ }^{2}$, В.П. Назьмов ${ }^{3,4}$, Н.В. Минаев ${ }^{1}$, Е.О. Епифанов ${ }^{1}$ \\ ${ }^{1}$ ФНИЦ „Кристаллография и фотоника“ РАН, Москва, Россия \\ 2 Московский государственный университет им. М.В. Ломоносова, Москва, Россия \\ ${ }^{3}$ Институт ядерной физики им. Г.И. Будкера СО РАН, Новосибирск, Россия \\ ${ }^{4}$ Институт химии твердого тела и механохимии СО РАН, Новосибирск, Россия \\ E-mail: sig74@mail.ru
}

Поступило в Редакцию 18 ноября 2021 г.

В окончательной редакции 20 декабря 2021 г.

Принято к публикации 20 декабря 2021 r.

На основе регулярных пористых полимерных мембран проведен синтез металлических и диэлектрических острийных структур с заданными морфологическими характеристиками. Получены медные структуры высотой $\sim 1 \mu \mathrm{m}$, диэлектрические острийные микроструктуры из иодноватой кислоты высотой $12 \mu \mathrm{m}$ и диаметром $1 \mu \mathrm{m}$. Обсуждается возможность применения таких оптических элементов для решения задач повышения эффективности детектирования ИК-излучения, усиления сигнала и конверсии в видимый и ближний ИК-диапазоны.

Ключевые слова: регулярные мембраны, острийные структуры, медь, иодноватая кислота, преобразования излучения.

DOI: 10.21883/PJTF.2022.06.52203.19084

Регулярные микроструктуры в настоящее время широко используются как элементы различных микроэлектронных изделий. Ведутся работы, направленные на повышение эффективности регистрации лазерного ИК-излучения [1]. Для этой цели актуально использование массивов упорядоченных металлических и диэлектрических острийных микроструктур. Выбор их материала и геометрии позволяет изменять глубину проникновения излучения и определяет особенности взаимодействия таких структур с излучением (вплоть до изменения соответствующей длины волны). Проведенные теоретические оценки коэффициента усиления локального поля показывают, что требования к геометрии металлических острийных структур и структур из оптически активных диэлектрических кристаллов различны. В первом случае (рис. 1,a) наибольший эффект можно ожидать, если высоты острий составляют величину порядка $0.5-1 \mu \mathrm{m}$, а во втором (рис. $1, b)$ желательно получать микрокристаллы с высотой порядка $10 \mu \mathrm{m}$ и диаметром несколько микрометров.

Следует отметить, что одним из основных достоинств рассматриваемых структур является их отчетливо выраженный периодический характер. Это делает их более эффективными, чем структуры на основе хаотично расположенных микрочастиц, используемые для генерации гармоник [2]. В настоящей работе рассмотрен способ получения упорядоченных массивов металлических острий и диэлектрических оптически активных микрокристаллов на полимерных пленках с регуляр- ными микропорами, сформированными с применением источника синхротронного излучения.

Был проведен синтез регулярных металлических поверхностных острийных структур с использованием пористых полимерных пленок. Диаметр пор и их глубина определялись условиями облучения полимера через титановую матрицу с периодическим рельефом [3]. Использовались полимерные пленки из полиэтилентерефталата (ПЭТФ) толщиной $10 \mu \mathrm{m}$. В результате такого облучения и последующего травления полимера удается получить достаточно совершенную пористую структуру с диаметром пор $\sim 1 \mu \mathrm{m}$ и глубиной от долей микрометра до толщины полимера $10 \mu \mathrm{m}$.

Процесс формирования регулярной металлической структуры включает несколько этапов. Тонкий слой серебра толщиной порядка $50 \mathrm{~nm}$ напылялся на поверхность исходного полимерного шаблона для создания и сохранения токопроводящих свойств, что использовалось в дальнейшем при осаждении меди. Методом электрохимического осаждения в потенциостатическом режиме на тонкий серебряный подслой наносились металлические острийные микроструктуры (в нашем случае медные) при комнатной температуре в течение $30 \mathrm{~min}$ [4]. Осаждение проводилось таким образом, чтобы медь полностью заполнила поры и сформировалась металлическая основа толщиной 10-20 $\mu \mathrm{m}$. Высота полученных металлических микроструктур составила $\sim 1 \mu \mathrm{m}$ при периоде повторяемости порядка единиц микрометров (рис. 2, $a$ ). 

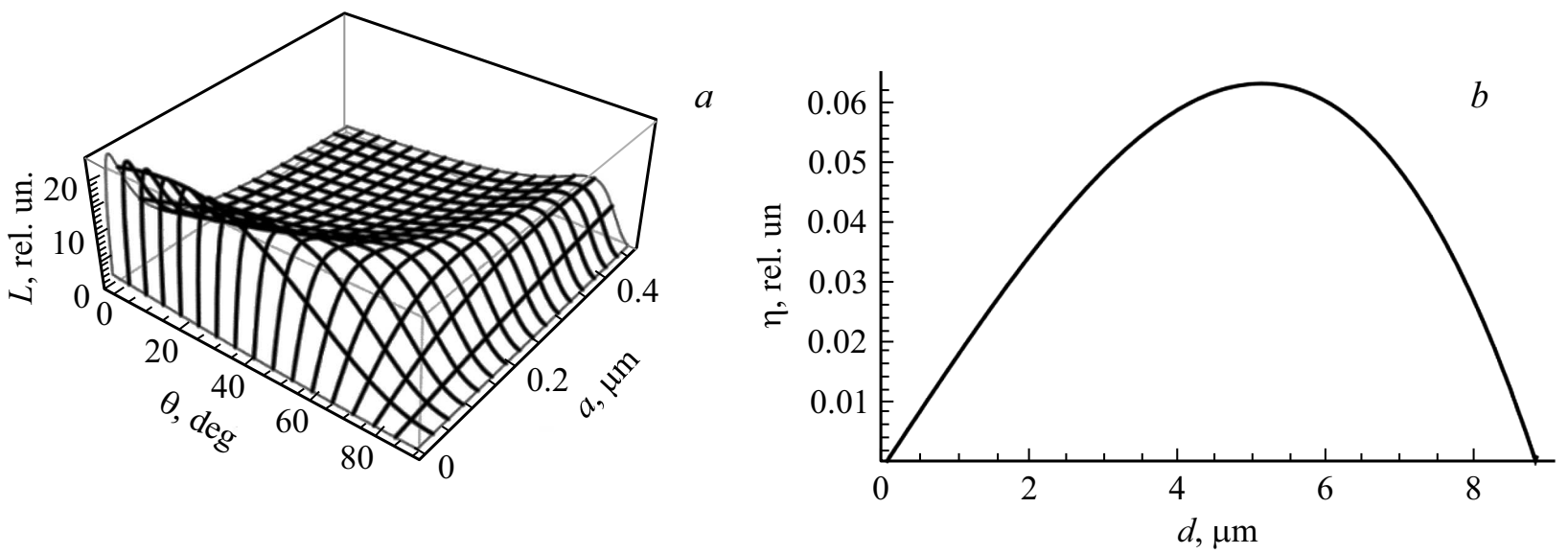

Рис. 1. $a-$ коэффициент усиления локального поля в условиях возбуждения плазмонного резонанса на периодической металлической поверхностной структуре в зависимости от угла падения $\theta$ и высоты профиля структуры $a$; $b-$ относительная эффективность генерации сигнала на частоте второй гармоники $\eta$ в диэлектрических микрокристаллах в зависимости от их диаметра $d$.
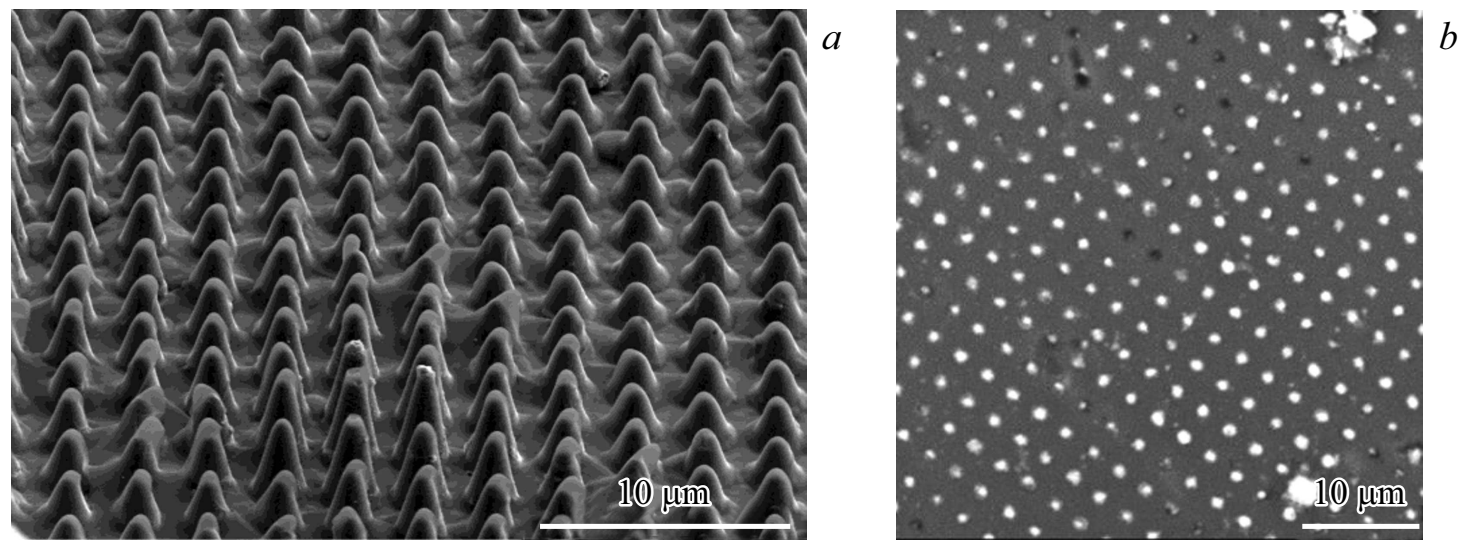

Рис. 2. Приповерхностные микроструктуры. $a-$ медь, растровый электронный микроскоп (PЭM) $\mathrm{FEI}$ Scios; $b-\mathrm{HIO}$, сканирующий электронный микроскоп Phenom PRO-X.

Полимерные пленки из ПЭТФ использовались также в качестве основы для формирования сплошной микроструктуры $\mathrm{HIO}_{3}$ [5] (рис. 2,b). Этот процесс был осуществлен погружением в пересыщенный до $11 \%$ раствор пористой пленки, которая затем высушивалась. В этом случае доза облучения подбиралась таким образом, чтобы полимерная пленка протравливалась насквозь.

Для получения протяженных микрокристаллов иодноватой кислоты использовался метод принудительного течения пересыщенного раствора через сквозные поры мембраны [5]. Получены острийные микроструктуры высотой порядка $12 \mu \mathrm{m}$ с поперечными размерами, соответствующими диаметру пор $\sim 1 \mu \mathrm{m}$. В каждой поре образуется несколько острийных структур диаметром $0.3-0.5 \mu \mathrm{m}$.

На рис. 3 представлены изображения поверхности $(a)$ и среза $(b)$, выполненного с помощью сфокусированного ионного пучка, регулярной мембраны с выращенными кристаллами $\mathrm{HIO}_{3}$.
Результаты энергодисперсионного анализа исследуемых образцов показывают содержание в них кислорода и иода.

Контроль периодичности синтезированных структур осуществлялся по оптической дифракции. Оптическая диагностика выявила высокую степень упорядоченности получаемых структур, а наблюдаемые экспериментально спектральные особенности отражения соответствуют возбуждению поверхностных плазмонных поляритонов.

На основе регулярных пористых мембран был проведен синтез металлических острийных структур высотой $\sim 1 \mu \mathrm{m}$. Металлические острийные структуры допускают нерезонансное усиление напряженности электрического поля, а также резонансное усиление, если частота первичного излучения попадает в область плазмонного резонанса металлической острийной структуры [1].

Получены острийные микроструктуры $\mathrm{HIO}_{3}$ высотой $\sim 12 \mu \mathrm{m}$ и диаметром пор $\sim 1 \mu \mathrm{m}$. В случае диэлектри- 

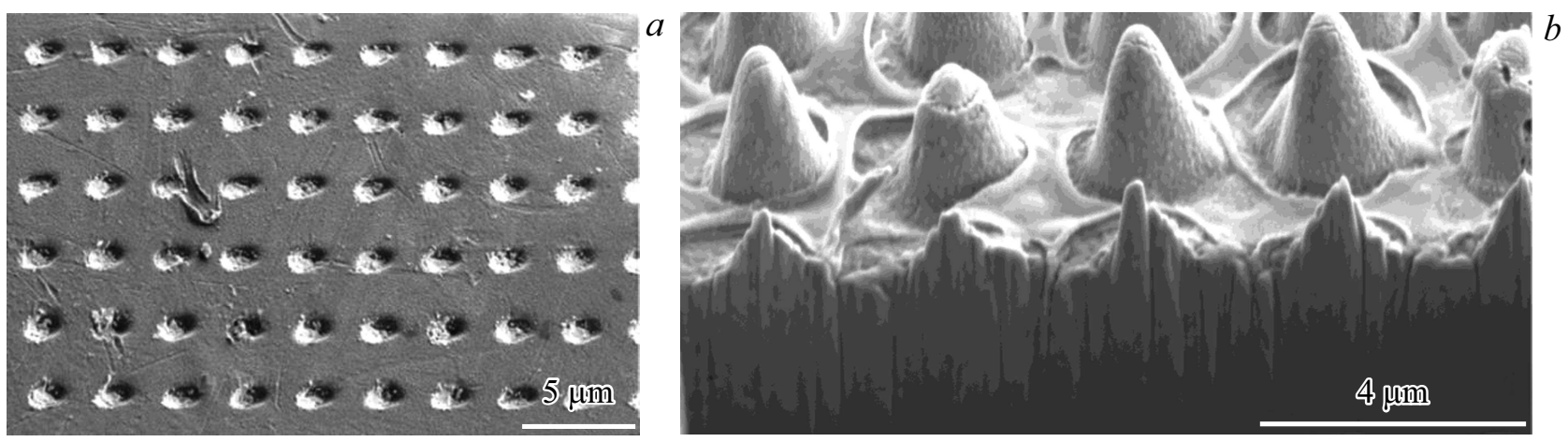

Рис. 3. РЭМ-изображения поверхности $(a)$ и среза $(b)$ регулярной мембраны с выращенными кристаллами $\mathrm{HIO}_{3}$.

ков поверхностная микроструктура нарушает симметрию свойств однородного материала и тем самым повышает эффективность генерации излучения на частоте второй гармоники при отражении от поверхности [6]. Расчеты показывают, что при дифракции поляризованного излучения на этих структурах, созданных в цилиндрических порах ПЭТФ-пленки, на поверхности цилиндра квадрат модуля электрического поля возрастает примерно в 9 раз. На краю цилиндра имеется сильная пространственная дисперсия, повышающая эффективность преобразования излучения в сигнал на частоте второй гармоники.

Таким образом, рассматриваемые микроструктуры являются перспективными в качестве оптических элементов для решения задач повышения эффективности детектирования ИК-излучения, усиления сигнала и конверсии в видимый и ближний ИК-диапазоны. Следует отметить, что проблема создания структур, период которых выдержан с высокой точностью (разброс меныше 1\%), актуальна и обсуждается применительно к разработке новых оптических элементов и источников лазерного излучения [7-9].

\section{Финансирование работы}

Работа выполнена при поддержке Министерства науки и высшего образования в рамках проведения исследований по государственному заданию ФНИЦ „Кристаллография и фотоника“" РАН в части выращивания диэлектрических микроструктур и гранта Российского фонда фундаментальных исследований 18-29-20090 в части выращивания металлических микроструктур и исследования возможности их применения для решения задач фотоники.

\section{Конфликт интересов}

Авторы заявляют, что у них нет конфликта интересов.

\section{Список литературы}

[1] C.L. Tan, H. Mohseni, Nanophotonics, 7 (1), 169 (2017). DOI: 10.1515/nanoph-2017-0061

[2] П.С. Самохвалов, Д.О. Володин, С.В. Бозрова, Д.С. Довженко, М.А. Звайгзне, П.А. Линьков, Г.О. Нифонтова, И.О. Петрова, А.В. Суханова, И.Р. Набиев, Письма в ЖТФ, 45 (7), 11 (2019). DOI: 10.21883/PJTF.2019.07.47528.17631 [P.S. Samokhvalov, D.O. Volodin, S.V. Bozrova, D.S. Dovzhenko, M.A. Zvaigzne, P.A. Lin'kov, G.O. Nifontova, I.O. Petrova, A.V. Sukhanova, I.R. Nabiev, Tech. Phys. Lett., 45 (4), 317 (2019). DOI: $10.1134 / \mathrm{S} 1063785019040151]$.

[3] V. Nazmov, B. Goldenberg, A. Vasiliev, V. Asadchikov, J. Micromech. Microeng., 31 (5), 055011 (2021). DOI: $10.1088 / 1361-6439 / \mathrm{abf331}$

[4] В.Е. Асадчиков, С.А. Бедин, А.Б. Васильев, И.Г. Дьячкова, Б.Г. Гольденберг, В.П. Назьмов, А.В. Андреев, А.А. Коновко, С.А. Решетов, Кристаллография, 66 (3), 467 (2021). DOI: 10.31857/S002347612103005X [V.E. Asadchikov, S.A. Bedin, A.B. Vasiliev, I.G. Dyachkova, B.G. Goldenberg, V.P. Nazmov, A.V. Andreev, A.A. Konovko, S.A. Reshetov, Crystallogr. Rep., 66 (3), 514 (2021). DOI: $10.1134 / \mathrm{S} 1063774521030056]$.

[5] В.В. Березкин, С.А. Бедин, А.Б. Васильев, Ю.В. Григорьев, В.П. Назьмов, Поверхность. Рентгеновские, синхротронные и нейтронные исследования, № 2, 39 (2020). DOI: 10.31857/S1028096020020041 [V.V. Berezkin, S.A. Bedin, A.B. Vasiliev, Yu.V. Grigoriev, V.P. Nazmov, J. Synch. Investig., 14 (1), 155 (2020). DOI: $10.1134 / \mathrm{S} 1027451020020044]$.

[6] A. de Hoogh, A. Opheij, M. Wulf, N. Rotenberg, L. Kuipers, ACS Photonics, 3 (8), 1446 (2016). DOI: $10.1021 /$ acsphotonics.5b00686

[7] Л.И. Горай, Е.В. Пирогов, М.В. Свечников, М.С. Соболев, Н.К. Поляков, Л.Г. Герчиков, Е.В. Никитина, А.С. Дашков, М.М. Борисов, С.Н. Якунин, А.Д. Буравлев, Письма в ЖТФ, 47 (15), 7 (2021). DOI: 10.21883/PJTF.2021.15.51225.18824 [L.I. Goray, E.V. Pirogov, M.V. Svechnikov, M.S. Sobolev, N.K. Polyakov, L.G. Gerchikov, E.V. Nikitina, A.S. Dashkov, M.M. Borisov, S.N. Yakunin, A.D. Bouravleuv, Tech. Phys. Lett. (2021). DOI: 10.1134/S1063785021080071]. 
[8] L.I. Goray, E.V. Pirogov, M.S. Sobolev, I.V. Ilkiv, A.S. Dashkov, Yu.A. Vainer, M.V. Svechnikov, P.A. Yunin, N.I. Chkhalo, A.D. Bouravlev, Semiconductors, 53 (14), 1910 (2019). DOI: $10.1134 / \mathrm{S} 1063782619140082$

[9] И.В. Алтухов, С.Е. Дижур, М.С. Каган, С.К. Папроцкий, Н.А. Хвальковский, А.Д. Буравлев, А.П. Васильев, Ю.М. Задиранов, Н.Д. Ильинская, А.А. Усикова, В.М. Устинов, Письма в ЖЭТФ, 103 (2), 128 (2016). DOI: 10.7868/S0370274X16020090 [I.V. Altukhov, S.E. Dizhur, M.S. Kagan, S.K. Paprotskiy, N.A. Khval'kovskii, A.D. Buravlev, A.P. Vasil'ev, Yu.M. Zadiranov, N.D. Il'inskaya, A.A. Usikova, V.M. Ustinov, JETP Lett., 103 (2), 122 (2016). DOI: $10.1134 / \mathrm{S} 002136401602003 \mathrm{X}$. 